\title{
Digestibilidade aparente de macrófitas aquáticas pela tilápia-do-nilo (Oreochromis niloticus) e qualidade da água em relação às concentrações de nutrientes
}

\author{
Gustavo Gonzaga Henry-Silva1 ${ }^{1}$, Antonio Fernando Monteiro Camargo², Luiz Edivaldo Pezzato ${ }^{3}$ \\ ${ }^{1}$ Doutor pelo Centro de Aqüicultura da UNESP - Jaboticabal, SP. \\ 2 Depto. de Ecologia - UNESP - Rio Claro, SP. \\ ${ }^{3}$ Depto. de Melhoramento e Nutrição Animal - UNESP - Botucatu, SP.
}

RESUMO - Objetivou-se com este estudo determinar os coeficientes de digestibilidade aparente (CDA) da proteína bruta e dos aminoácidos de duas espécies de macrófitas aquáticas flutuantes (Eichhornia crassipes e Pistia stratiotes) pela tilápiado-nilo (Oreochromis niloticus) e verificar a qualidade da água dos aquários de digestibilidade em relação às concentrações de nitrogênio e fósforo. Foram elaboradas três rações, marcadas com $0,10 \%$ de óxido de cromo-III, sendo uma ração-referência (purificada) e as demais contendo $30 \%$ de cada uma das macrófitas aquáticas. As tilápias-do-nilo (58,8 $\pm 18,5 \mathrm{~g})$ foram alimentadas até a saciedade aparente e a coleta de fezes foi feita pelo sistema Guelph modificado. Os CDA médios da proteína e dos aminoácidos foram, respectivamente, 93,17 e 93,32\% para a ração-referência; 59,23 e $60,35 \%$ para E. crassipes; e 52,24 e $57,40 \%$ para $P$. stratiotes. Não foram constatadas diferenças significativas entre os valores de CDA da proteína e dos aminoácidos dos ingredientes vegetais. Os resultados obtidos demonstraram reduzida eficiência da tilápia-do-nilo em assimilar a maioria dos aminoácidos de E. crassipes e P. stratiotes. As excretas das tilápias-do-nilo contribuíram para o aumento das concentrações de nitrogênio e fósforo na água dos aquários, independentemente da ração fornecida.

Palavras-chave: aminoácidos, Eichhornia crassipes, eutrofização artificial ingredientes, nutrientes, Pistia stratiotes

\section{Apparent digestibility of aquatic macrophytes by Nile tilapia (Oreochromis niloticus) and water quality in relation nutrients concentrations}

\begin{abstract}
The objectives of this trial were to determine the apparent digestibility coefficients (ADC) of crude protein and amino acids for two species of free floating aquatic macrophytes (Eichhornia crassipes and Pistia stratiotes) by Nile tilapia (Oreochromis niloticus) and to determine the water quality of digestibility aquariums in relation nitrogen and phosphorus concentrations. Tree feeds were developments, containing $0.10 \%$ of chromic oxide - III, one being the reference diet (purified) and the others containing $30 \%$ of aquatic macrophytes. The Nile tilapias $(58.8 \pm 18.5 \mathrm{~g})$ were fed to apparent satiation and the faeces were collected by modified Guelph system. The average ADC of crude protein and amino acids were, respectively, 93.17 and $93.32 \%$ for diet reference; 59.23 and $60.35 \%$ for E. crassipes; and 52.24 and $57.40 \%$ for P. stratiotes. No significant differences were observed among the ADC of protein and of amino acids of the plants ingredients. The results showed lower efficiency by tilapia of Nile in assimilate the most amino acids of the E. crassipes and P. stratiotes. It is possible to conclude that excretory products in the Nile tilapia increase the concentrations of nitrogen and phosphorus, independent of feed.
\end{abstract}

Key Words: amino acids, artificial eutrophication, Eichhornia crassipes, feedstuffs, nutrients, Pistia stratiotes

\section{Introdução}

As rações utilizadas na aqüicultura, além de atenderem às exigências nutricionais das espécies, devem proporcionar reduzidos excedentes de nutrientes, visando minimizar os impactos negativos sobre os sistemas de criação e os ecossistemas aquáticos (Valenti, 2000; Henry-Silva, 2001). Os princípios que devem nortear o desenvolvimento de dietas com baixa carga poluente são a digestibilidade elevada dos ingredientes, a aceitabilidade da ração pelos organismos criados, o balanço adequado dos nutrientes, a estabilidade elevada do pélete e o tamanho compatível com a capacidade de ingestão dos organismos aquáticos (Midlen \& Redding, 1998).

Nas próximas décadas, novas oportunidades devem surgir com os avanços na investigação e no desenvolvimento de tecnologias em aqüicultura e um dos aspectos promissores envolve a utilização de plantas aquáticas como fonte de nutrientes ematividades de piscicultura(El-Sayed, 1999; NACA/ FAO, 2000). De fato, alguns trabalhos têm demonstrado a 
viabilidade de aproveitamento de macrófitas aquáticas na alimentação de peixes, podendo se destacar os realizados por Santiago et al. (1988), Essa (1997) e Naegel (1997).

As macrófitas aquáticas têm sido utilizadas com êxito no tratamento de efluentes urbanos e de aqüicultura (Brix, 1997; Henry-Silva, 2005). No entanto, ainda é reduzido o aproveitamento da biomassa vegetal produzida nestes sistemas de tratamento (Henry-Silva \& Camargo, 2002). Nesse contexto, objetivou-se determinar os coeficientes de digestibilidade da proteína bruta e dos aminoácidos das macrófitas aquáticas flutuantes Eichhornia crassipes e Pistia stratiotes pela tilápia-do-nilo (Oreochromis niloticus) e verificar as concentrações de nitrogênio e fósforo na água dos aquários de digestibilidade, visando avaliar o potencial de aproveitamento desses vegetais em rações animais e o impacto das rações sobre a qualidade da água.

\section{Material e Métodos}

O experimento foi realizado no período de janeiro a fevereiro de 2004, na Universidade Estadual Paulista(UNESP), no Laboratório de Nutrição de Organismos Aquáticos da Faculdade de Medicina Veterinária e Zootecnia, campus de Botucatu, Unidade Integrada ao Centro de Aqüicultura da UNESP (CAUNESP).

No ensaio de digestibilidade, foram utilizadas 60 tilápiasdo-nilo (O. niloticus) revertidas durante a fase larval, com peso vivo de $58,8 \pm 18,5 \mathrm{~g}$ (dez indivíduos por aquário). As macrófitas aquáticas (E. crassipes e $P$. stratiotes) utilizadas nas rações foram coletadas em sistemas de tratamento de efluentes de criação de camarão-d' água-doce (Macrobrachium amazonicum).

Os coeficientes de digestibilidade aparente (CDA) da proteína e dos aminoácidos foram determinados a partir de uma ração-referência purificada, elaborada com base na proteína da albumina e da gelatina (Tabela 1). Duas dietasteste foram confeccionadas para avaliação da digestibilidade das macrófitas aquáticas. As biomassas totais de $E$. crassipes e $P$. stratiotes substituíram, cada uma, 30\% da dieta purificada. As farinhas de ambas as espécies foram obtidas segundo procedimento proposto por Nakanishi (2000). Na Tabela 2 são apresentados os valores de aminoácidos e de PB da ração-referência e das macrófitas aquáticas.

Antes do início do experimento, os peixes foram mantidos por cinco dias nos tanques de alimentação, para adaptação às instalações, ao manejo e às dietas experimentais. Foram alojados em seis tanques-rede de formato circular $(80$ $\mathrm{cm}$ de diâmetro e $60 \mathrm{~cm}$ de altura). Cada tanque-rede fez parte
Tabela 1 - Composição percentual da ração-referência, expressa em $100 \%$ da matéria seca

Table 1 - Ingredient composition of the reference diet. Values expressed in the $100 \%$ of the dry matter

\begin{tabular}{|c|c|}
\hline $\begin{array}{l}\text { Ingredient } \\
\text { Ingredient }\end{array}$ & $\%$ \\
\hline Albumina & 32,50 \\
\hline \multicolumn{2}{|l|}{ Albumine } \\
\hline Gelatina & 5,50 \\
\hline \multicolumn{2}{|l|}{ Gelatine } \\
\hline Amido de milho & 47,15 \\
\hline \multicolumn{2}{|l|}{ Corn starch } \\
\hline Oleo de soja & 3,80 \\
\hline \multicolumn{2}{|l|}{ Soybean oil } \\
\hline a-celulose $e^{1}$ & 6,60 \\
\hline \multicolumn{2}{|l|}{ a-cellulose } \\
\hline Fosfato bicalcico & 3,70 \\
\hline \multicolumn{2}{|l|}{ Dicalcium phosphate } \\
\hline Premix min. e vit. ${ }^{2}$ & 0,50 \\
\hline \multicolumn{2}{|l|}{ Mineral and vitamin mix } \\
\hline Vitamina $C^{3}$ & 0,08 \\
\hline \multicolumn{2}{|l|}{ Vitamin $C$} \\
\hline Sal comum & 0,15 \\
\hline \multicolumn{2}{|l|}{ Salt } \\
\hline $\mathrm{BHT}^{4}$ & 0,02 \\
\hline Oxido de cromio & 0,10 \\
\hline Total & 100,00 \\
\hline \multicolumn{2}{|c|}{ 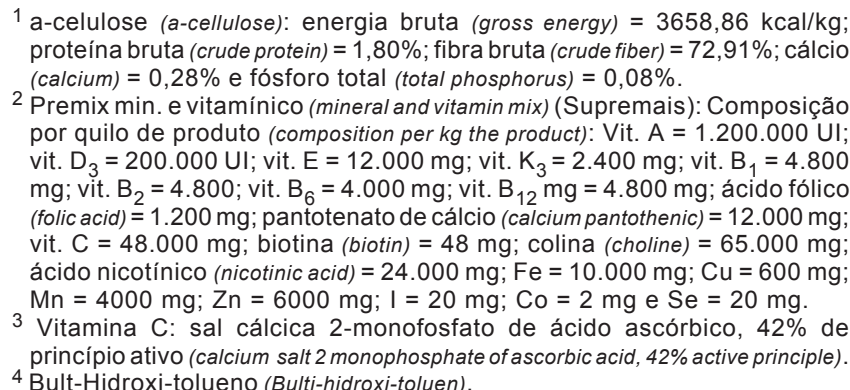 } \\
\hline
\end{tabular}

de um conjunto de aquários circulares (aquários de alimentação), confeccionados em fibra de vidro, com capacidade de 250 L de água, em um sistema de circulação fechado, com aeração e controle de temperatura. Nesses aquários, os peixes permaneceram durante o dia (de 8 às $17 \mathrm{~h}$ ) recebendo as rações à vontade por arraçoamento manual. Posteriormente, os tanques-rede foram transferidos para os aquários de digestibilidade, um para cada tanque-rede, com capacidade para $300 \mathrm{~L}$. As fezes coletadas foram congeladas a $20^{\circ} \mathrm{C}$, armazenadas e, posteriormente, desidratadas a $52^{\circ} \mathrm{C}$ por 48 horas, moídas e homogeneizadas para as análises químicas.

Os CDA foram determinados pelo método indireto, utilizando-se cromo-III como indicador inerte - $0,1 \%$ (Lanna et al., 2004). Os CDA da PB e dos aminoácidos da raçãoreferência e das rações com $30 \%$ das macrófitas aquáticas foram calculados de acordo com a seguinte equação (Nose, 1966): 
Tabela 2 - Composições de proteína bruta e de aminoácidos da ração-referência e dos ingredientes (100\% da matéria seca)

Table 2 - Crude protein and amino acid compositions of carcass, reference diet and ingredients (100\% of dry matter)

$\begin{array}{lccc}\text { Aminoácido }(\%) & \begin{array}{c}\text { Ração-referência } \\ \text { Amino acid }\end{array} & \text { E. crassipesence diet } & P . \text { stratiotes }\end{array}$

Essencial

Essential

\begin{tabular}{llll} 
Arg & 1,95 & 0,57 & 0,97 \\
His & 0,65 & 0,22 & 0,30 \\
Ile & 1,61 & 0,57 & 0,78 \\
Leu & 2,63 & 1,03 & 1,40 \\
Lis & 1,86 & 0,55 & 0,85 \\
Met & 1,05 & 0,07 & 0,08 \\
Fen & 1,84 & 0,66 & 0,91 \\
Tre & 1,22 & 0,69 & 0,75 \\
Trp & 0,36 & 0,14 & 0,13 \\
Val & 2,07 & 0,78 & 1,07 \\
\hline
\end{tabular}

Não-essencial

Non essential

\begin{tabular}{llll}
\hline Asp & 2,85 & 1,54 & 1,46 \\
Glu & 4,06 & 1,38 & 1,79 \\
Ala & 2,16 & 0,85 & 1,10 \\
Cis & 0,53 & 0,04 & 0,09 \\
Gli & 2,15 & 0,75 & 0,97 \\
Ser & 1,76 & 0,59 & 0,75 \\
Pro & 1,70 & 0,49 & 0,75 \\
Tir & 0,70 & 0,27 & 0,44 \\
\hline Proteína bruta & 32,60 & 12,45 & 15,01 \\
Crude protein & & & \\
\hline
\end{tabular}

$$
C D A(\%)=100-\left[100\left(\frac{\% \mathrm{Cr}_{2} \mathrm{O}_{3 r}}{\% C r_{2} \mathrm{O}_{3}}\right) x\left(\frac{\% N_{f}}{\% N_{r}}\right)\right]
$$

em que: $\mathrm{CDA}=$ coeficiente de digestibilidade aparente da variável analisada (\%); $\% \mathrm{Cr}_{2} \mathrm{O}_{3 \mathrm{r}}=$ porcentagem de óxido de cromo na ração; $\% \mathrm{Cr}_{2} \mathrm{O}_{3 \mathrm{f}}=$ porcentagem de óxido de cromo nas fezes; $\% \mathrm{~N}_{\mathrm{f}}=$ porcentagem da variável nas fezes; $\% \mathrm{~N}_{\mathrm{r}}$ $=$ porcentagem da variável na ração.

Os CDA da PB e dos aminoácidos exclusivamente dos ingredientes (E. crassipes e $P$. stratiotes) foram calculados de acordo com a equação descrita por Cho \& Slinger (1979):

$$
C D A_{N}(\%)=\frac{C D A_{R T}-C D A_{R R} \cdot x}{y}
$$

em que: $\mathrm{CDA}_{\mathrm{N}}=$ coeficiente de digestibilidade aparente da variável analisada $; \mathrm{CDA}_{\mathrm{RT}}=$ coeficiente de digestibilidade aparente da variável na ração-teste; $\mathrm{CDA}_{\mathrm{RR}}=$ coeficiente de digestibilidade aparente da variável na ração-referência; $\mathrm{x}=$ proporção da ração-referência $(70 \%) ; \mathrm{y}=$ proporção da ração-teste (30\%).

As análises bromatológicas dos alimentos, das rações e das fezes foram realizadas segundo os protocolos da AOAC (1990) e as análises das concentrações de cromo-III das rações e das fezes foram feitas conforme descrito por Graner(1972).

O oxigênio dissolvido e a temperatura da água dos aquários foram mantidos constantes por meio, respectivamente, de aquecedores e de pedras porosas acopladas a um aerador central. Os valores médios e desvios-padrão das variáveis limnológicas da água dos aquários foram: $25,26 \pm 0,17^{\circ} \mathrm{C}$ de temperatura, $6,60 \pm 0,12$ de $\mathrm{pH}$ e $6,35 \pm 0,20$ $\mathrm{mg} / \mathrm{L}$ de oxigênio dissolvido e situaram-se na faixa de conforto para a espécie (Castagnolli \& Cyrino, 1986; Boscolo et al., 2004).

Foram coletadas amostras de água dos aquários de digestibilidade e de sua fonte de abastecimento (água de poço), no intuito de verificar a influência das excretas dos peixes alimentados com as diferentes rações sobre as concentrações de nitrogênio e fósforo totais na água. As amostras foram obtidas após a permanência dos peixes, durante 15 horas, nos aquários (um ciclo de coletas de fezes). As determinações de nitrogênio total (NT) foram realizadas segundo método descrito por Mackereth et al. (1978) e as de fósforo total (PT), conforme descrito por Golterman et al. (1978).

A análise de variância de uma classificação e o teste Tukey ( $5 \%$ de probabilidade) foram aplicados no intuito de verificar diferenças entre os coeficientes de digestibilidade e as concentrações de nitrogênio e fósforo da água dos aquários de digestibilidade.

\section{Resultados e Discussão}

Durante todo o período experimental, não houve mortalidade ou alterações no consumo alimentar tanto da raçãoreferência quanto das rações-teste, com E. crassipes e $P$. stratiotes.

Não foram constadas diferenças significativas entre os CDA da PB e dos aminoácidos das duas macrófitas. No entanto, os valores de CDA destas variáveis foram significativamente inferiores aos da ração-referência, indicando a menor eficiência da tilápia-do-nilo em assimilar a proteína e os aminoácidos contidos na biomassa de E. crassipes e $P$. stratiotes (Tabela 3). Conforme relatado por Furuya et al. (2001), a elevada digestibilidade da ração-referência sugere a possibilidade de substituição da caseína por albumina em estudos de avaliação da digestibilidade de nutrientes.

Durante todo o período experimental, observou-se menor tempo de coleta das fezes das tilápias-do-nilo alimentadas com as rações com as macrófitas aquáticas, em relação ao tempo para coletadas fezes das tilápias, alimentadas com a ração-referência, o que, provavelmente, esteve 
Tabela 3 - Coeficientes de digestibilidade aparente da proteína e dos aminoácidos da ração-referência e dos ingredientes. Valores expressos em $100 \%$ da matéria seca

Table 3 - $\quad$ Apparent digestibility coefficients of protein and amino acid for reference diet and ingredients. Values expressed in $100 \%$ of dry matter

\begin{tabular}{lccc}
\hline $\begin{array}{l}\text { Aminoácido (\%) } \\
\text { Amino acid }\end{array}$ & $\begin{array}{c}\text { Ração-referência } \\
\text { Reference diet }\end{array}$ & E. crassipes & $P$. stratiotes \\
\hline Essencial & & & \\
Essential & & & \\
Arg & 94,99 & 64,03 & 59,84 \\
His & 93,46 & 60,28 & 55,84 \\
Ile & 92,39 & 53,35 & 55,09 \\
Leu & 92,87 & 57,44 & 55,28 \\
Met & 93,28 & 61,54 & 54,57 \\
Lis & 94,30 & 98,21 & 98,70 \\
Fen & 92,90 & 61,10 & 55,93 \\
Tre & 90,25 & 46,33 & 41,51 \\
Trp & 94,53 & 77,35 & 72,19 \\
Val & 92,69 & 54,14 & 51,20
\end{tabular}

Não-essencial

Non essential

\begin{tabular}{lccc}
\hline Asp & 92,62 & 60,26 & 54,37 \\
Glu & 93,04 & 66,55 & 64,42 \\
Ala & 92,19 & 46,11 & 46,15 \\
Cis & 97,08 & 84,64 & 82,33 \\
Gli & 92,49 & 37,49 & 40,38 \\
Ser & 93,03 & 64,20 & 57,29 \\
Pro & 93,39 & 40,78 & 45,87 \\
Tir & 94,48 & 50,69 & 47,41 \\
Média & $93,32^{\mathrm{a}}$ & $60,35^{\mathrm{b}}$ & $57,40^{\mathrm{b}}$ \\
Average & & \\
Proteína bruta & $93,17^{\mathrm{a}}$ & $59,23^{\mathrm{b}}$ & $52,24^{\mathrm{b}}$ \\
Crude protein & & & \\
\hline
\end{tabular}

Médias seguidas por letras distintas indicam diferenças significativas $(P<0,05)$ pelo teste Tukey.

Means followed by different letter differ $(P<0.05)$ by Tukey test.

relacionado ao trânsito mais rápido das rações-teste no trato digestório, visto que $P$. stratiotes, e especialmente E. crassipes, possuem valores elevados de fibra (HenrySilva \& Camargo, 2000). Segundo Lanna et al. (2004), o aumento do teor de fibra da dieta diminui significativamente o tempo de trânsito gastrintestinal.

Os resultados de CDA da proteína bruta de E. crassipes $(59,2 \%)$ e de $P$. stratiotes (52,2\%) foram superiores aos do milho (30,0\%), em estudo com bagre africano, Clarias gariepinus (Clay, 1981). Entretanto, estes resultados foram menores que os obtidos com o farelo de girassol $(65,4 \%)$ e o farelo de soja (84,3\%). Pezzato et al. (2002), verificando o CDA da proteína de ingredientes de origem vegetal em tilápia-do-nilo, encontraram valores de CDA de 23 a 45\% superiores aos registrados neste estudo com as macrófitas aquáticas. No entanto, os valores de CDA de proteína de $E$. crassipes e de $P$. stratiotes foram superiores aos verificados pelo mesmo autor para farinha de sangue $(50,7 \%)$ e farinha de penas $(29,12 \%)$.

A digestibilidade de ingredientes vegetais não-convencionais é bastante variável, em decorrência da espécie a ser testada e das proporções em que estes ingredientes são incorporados às rações. Wee (1991), utilizando a biomassa de $E$. crassipes (matéria seca) na alimentação de Labeo rohita, constatou CDA da proteína de 71 e $63 \%$ para níveis de inclusão deste vegetal de 20 e $40 \%$, respectivamente, e observou que, para o controle com farinha de peixe, o CDA da proteína foi de 79\%. Esse autor relatou ainda que a farinha de folhas de mandioca (Manihot esculenta), utilizada nas proporções de 20,40,60 e 100\% das necessidades de proteína de $O$. niloticus, apresentou CDA de 64, 50,35 e $18 \%$, respectivamente.

Os valores médios de CDA dos aminoácidos (essenciais e não-essenciais) foram de 60,35 e $57,40 \%$ para $E$. crassipes e $P$. stratiotes, respectivamente. Entre os aminoácidos essenciais, a metionina apresentou o maior CDA, com valores de $98,21 \%$ para $E$. crassipes e de $98,70 \%$ para $P$. stratiotes. Estes valores altos de CDA de metionina das macrófitas aquáticas pela tilápia-do-nilo provavelmente se devem aos baixos valores deste aminoácido na biomassa de ambas as macrófitas aquáticas e que, provavelmente, foi prontamente assimilado pelos peixes. O triptofano também apresentou CDA superior à média dos aminoácidos essenciais para ambas as macrófitas aquáticas testadas.

A treonina, no entanto, apresentou os menores valores de CDA para as macrófitas aquáticas, inclusive para a raçãoreferência, como observado também por Furuya et al. (2001), ao avaliarem os CDA de aminoácidos do milho, farelo de trigo, farelo de soja e farinha de peixe, pela tilápia-do-nilo, e por Allan et al. (2000), utilizando ingredientes alternativos na dieta da perca prateada (Bydyanus bidyanus).

Entre os aminoácidos não-essenciais, o maior CDA registrado foi o da cistina $(84,64 \%$, em $E$. crassipes, e 82,33\%, em $P$. stratiotes $)$ e os menores, os da glicina $(37,49 \%$, em E. crassipes, e 40,38\%, em P. stratiotes). Esses menores valores de CDA da glicina foram semelhantes aos observados por Hossain \& Jauncey (1989), ao testarem a digestibilidade da farinha de peixe pela carpa comum (Cyprinus carpio), e por Anderson et al. (1992), ao utilizarem o farelo de soja na dieta de salmão do Atlântico (Salmo salar).

Os valores médios de CDA da PB e dos aminoácidos das macrófitas aquáticas analisadas foram semelhantes, corroborando os resultados obtidos por Furuya et al. (2001) e Borghesi (2004). Entretanto, é importante ressaltar a importância da determinação da digestibilidade individual dos aminoácidos, pois, embora exista alta correlação entre 
os CDA da proteína e dos aminoácidos, o CDA da proteína nem sempre reflete a digestibilidade de cada um dos aminoácidos (Matsumoto et al., 1996). De fato, neste estudo, o CDA da metionina foi aproximadamente 2,5 vezes superior ao da glicina para ambas as macrófitas aquáticas, demonstrando que, para a formulação de dietas balanceadas, é necessário o conhecimento dos CDA dos aminoácidos dos ingredientes, visto que o coeficiente de digestibilidade da proteína não reflete os coeficientes de digestibilidade de todos os aminoácidos.

$\mathrm{Na}$ Tabela 4 encontram-se os valores de proteína e de aminoácidos digestíveis da ração-referência e das macrófitas aquáticas. Embora inferiores aos encontrados por Furuya et al. (2001) para o farelo de trigo e o farelo de soja, os valores de proteína e aminoácidos digestíveis foram semelhantes aos obtidos por esses autores para o milho. Pode-se, portanto, inferir que a tilápia-do-nilo, por apresentar adaptações morfológicas e fisiológicas, aproveita a proteína e os aminoácidos de origem vegetal.

As excretas das tilápias-do-nilo contribuíram para o aumento das concentrações de nutrientes na água dos

Tabela 4 - Valores médios de proteína e aminoácidos digestíveis da ração-referência e dos ingredientes. Valores expressos em $100 \%$ da matéria seca

Table 4 - Values of digestible protein and amino acids for reference diet and ingredients. Values expressed in the $100 \%$ of the dry matter

Aminoácido (\%) Ração-referência E. crassipes $\quad$. stratiotes Amino acid Reference diet

\section{Essencial}

Essential

\begin{tabular}{llll} 
Arg & 1,85 & 0,36 & 0,58 \\
His & 0,61 & 0,13 & 0,17 \\
Ile & 1,49 & 0,30 & 0,43 \\
Leu & 2,44 & 0,59 & 0,77 \\
Met & 1,74 & 0,34 & 0,46 \\
Lis & 0,99 & 0,07 & 0,08 \\
Fen & 1,71 & 0,42 & 0,51 \\
Tre & 1,10 & 0,32 & 0,31 \\
Trp & 0,34 & 0,11 & 0,09 \\
Val & 1,92 & 0,42 & 0,55 \\
\hline
\end{tabular}

Não-essencial

Non essential

\begin{tabular}{lcll}
\hline Asp & 2,64 & 0,93 & 0,79 \\
Glu & 3,78 & 0,92 & 1,15 \\
Ala & 1,99 & 0,39 & 0,51 \\
Cis & 0,51 & 0,03 & 0,07 \\
Gli & 1,99 & 0,28 & 0,39 \\
Ser & 1,64 & 0,38 & 0,43 \\
Pro & 1,59 & 0,20 & 0,34 \\
Tir & 0,66 & 0,14 & 0,21 \\
\hline Proteína digestível & 30,37 & 7,37 & 7,84 \\
Digestible protein & & & \\
\hline
\end{tabular}

aquários de digestibilidade, independentemente da ração fornecida, visto que os valores de nitrogênio e fósforo da água de abastecimento foram significativamente inferiores aos obtidos na água dos aquários de digestibilidade. Os teores de PT foram os que apresentaram maiores incrementos médios. Nos aquários das tilápias alimentadas com a ração-referência, este aumento foi de $273,3 \%$ em relação ao observado na água de abastecimento, enquanto, para os teores de NT, esse incremento foi de $42,8 \%$. Nos aquários com as tilápias alimentadas com as rações contendo $E$. crassipes e $P$. stratiotes, os valores de incremento foram, respectivamente, de 489,4 e 526,9 para PT e de 36,5 e 52,4\% para NT (Figura 1).

Diferenças significativas entre os tratamentos foram obtidas apenas para os teores de PT, sendo encontrados
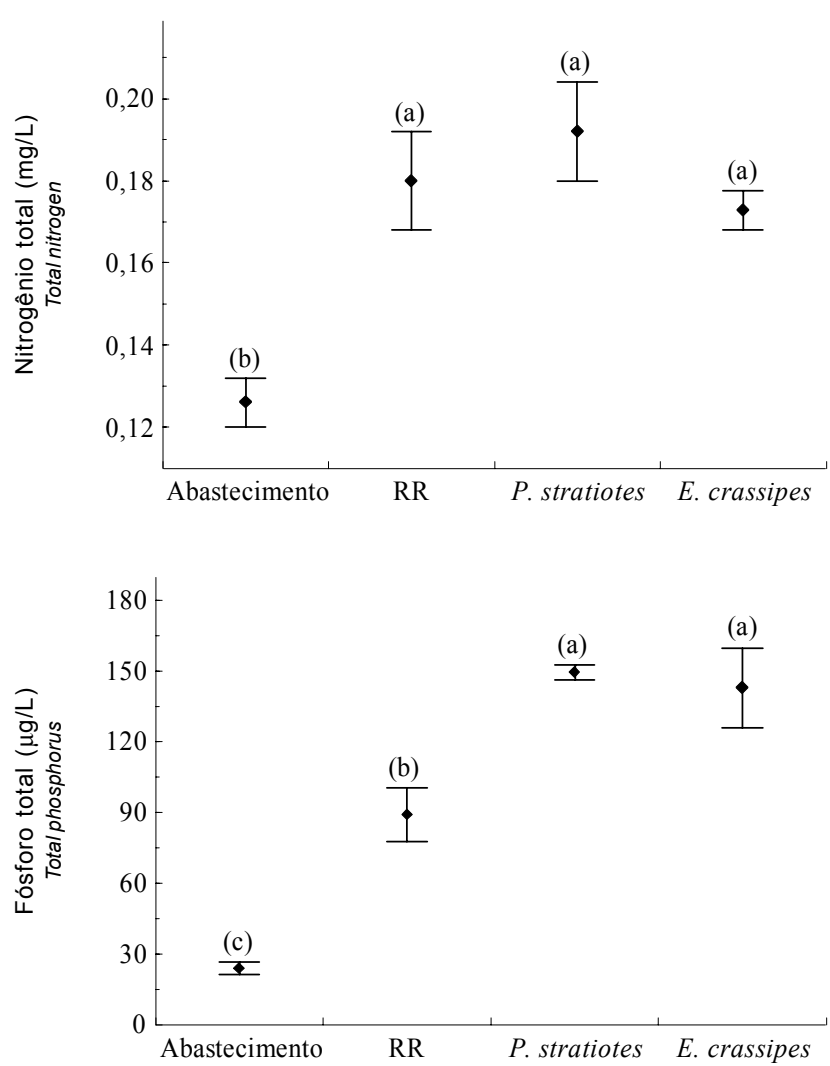

Figura 1 - Valores médios e desvios-padrão de nitrogênio total e fósforo total da água de abastecimento e da água dos aquários de digestibilidade com as tilápias-donilo alimentadas com a ração-referência (RR) e com as rações contendo $P$. stratiotes e $E$. crassipes.

Figure 1 - Average values and standard deviations of total nitrogen and total phosphorus of fresh water supply and of the water of digestibility aquarium with Nile tilapia fed with reference diet (RD) and diet contained P. stratiotes and E. crassipes.

Médias seguidas por letras distintas indicam diferenças significativas $(P<0,05)$ pelo teste Tukey.

Means followed by different letter indicate significantly different $(P<0.05)$ by Tukey test. 
valores significativamente superiores na água dos aquários com os peixes alimentados com as macrófitas aquáticas. Estes maiores valores de PT provavelmente estiveram associados à dificuldade que os animais monogástricos possuem em assimilar o fósforo em dietas à base de plantas, o que resulta na eliminação desse nutriente nas fezes. Em rações com ingredientes vegetais, a maior parte do fósforo pode estar complexada na forma de fósforo fítico (fitato), tornando este macronutriente indisponível para os peixes, que não possuem enzimas capazes de disponibilizá-lo. É importante ressaltar que o incremento de fósforo pode ser prejudicial aos sistemas de criação e aos ecossistemas aquáticos em que os efluentes são lançados, especialmente pelo fato de este nutriente ser um dos principais responsáveis pela eutrofização artificial.

\section{Conclusões}

Os coeficientes de digestibilidade aparente da proteína e dos aminoácidos de E. crassipes e $P$. stratiotes pela tilápia-do-nilo foram semelhantes.

Os coeficientes de digestibilidade aparente da proteína não refletiram os coeficientes de digestibilidade de todos os aminoácidos.

A utilização de E. crassipes e $P$. stratiotes em rações animais é recomendada apenas em substituição a ingredientes que apresentem valores de digestibilidade da proteína e dos aminoácidos inferiores ou semelhantes aos obtidos neste estudo.

A alimentação de tilápias com macrófitas aquáticas aumentou as concentrações de fósforo total na água dos aquários de digestibilidade.

\section{Agradecimento}

ÀFAPESP, pelo suporte financeiro(Processo: 02/04131-8).

Ao Prof. Dr. Wagner Cotroni Valenti e aos pós-graduandos DarioFalcon, GiovaniSampaio Gonçalvese Leonardo Tachibana, pelo auxílio no desenvolvimento dos experimentos.

\section{Literatura Citada}

ALLAN, G.L.; PARKINSON, S.; BOOTH, M.A. et al. Replacement of fish meal in diets for Australian silver perch. Bidyanus bidyanus: I. Digestibility of alternative ingredients. Aquaculture, v.186, p.293-310, 2000.

ANDERSON, J.S.; LALL, S.P.; ANDERSON, D.M. et al. Apparent and true availability of amino acids from common feed ingredients for Atlantic salmon (Salmo solar) reared in sea water. Aquaculture, v.108, p.111-114, 1992.

ASSOCIATION OF OFFICIAL ANALYTICAL CHEMISTS - AOAC. Official methods of analysis. Washington, D.C.: 1990. 1015p.
BORGHESI, R. Avaliação físico-química, nutricional e biológica das silagens ácida, biológica e enzimática elaboradas com descartes e resíduo do beneficiamento da tilápia do Nilo (Oreochromis niloticus). Piracicaba: Universidade de São Paulo, 2004. 79p. Dissertação (Mestrado em Ciências) - Universidade de São Paulo, 2004.

BOSCOLO, W.R.; HAYASHI, C.; MEURES F. et al. Digestibilidade aparente da energia e proteína das farinhas de resíduo da filetagem da tilápia do Nilo (Oreochromis niloticus) e da corvina (Plagioscion squamosissimus) e farinha integral do camarão canela (Macrobrachium amazonicum) para tilápia do Nilo. Revista Brasileira de Zootecnia, v.33, n.1, p.8-13, 2004.

BOYD, C.E. Water quality in ponds for aquaculture. Alabama: Auburn University, 1990. 482p.

BRIX, H. Do macrophytes play a role in constructed treatment wetlands? Water Science Technology, v.35, n.5, p.11-17, 1997.

CHO, C.Y.; SLINGER, S.I. Apparent digestibility measurement in feedstuff for ranibow trout. In: WORD SYMPOSIUM ON FINFISH NUTRITION AND FISHFEED TECHNOLOGY, 1979, Hamburg. Proceedings... Heeneman: HALVER, J.; TIEWS, K., 1979, p.239-247.

CLAY, D. Utilization of plant materials by juvenile African catfish (Clarias gariepinus) and its importance in fish culture. Journal Limnology Society South African, v.7, n.2, p.47-56, 1981

EL-SAYED, A.F.M. Alternative dietary protein sources for farmed tilapia, Oreochromis spp. Aquaculture, v.179, p.149-168, 1999.

ESSA, M.A. Utilisation of some aquatic plants in diets for Nile tilapia, Oreochromis niloticus, fingerlings. Egypt Journal Aquatic Biology Fish, v.1, n.2, p.19-34, 1997.

FURUYA, W.M.; PEZZATO, L.E.; PEZZATO, A.C. et al. Coeficientes de digestibilidade e valores de aminoácidos digestíveis de alguns ingredientes para Tilápia do Nilo (Oreochromis niloticus). Revista Brasileira de Zootecnia, v.30, n.4, p.1143-1149, 2001

GOLTERMAN, H.L.; CLYNO, R.S.; OHNSTAD, M.A.M. Methods for chemical analysis of fresh water. Boston: Blackwell, 1978. 214p.

GRANER, C.A.F. Determinação do crômio pelo método colorimétrico da s-difenilcarbazida. Botucatu: Faculdade de Ciências Médicas e Biológicas, 1972. 102p. Tese (Doutorado em Ciências) - Faculdade de Ciências Médicas e Biológicas, 1972 .

HENRY-SILVA, G.G. Tratamento de efluentes de carcinicultura por macrófitas aquáticas, interações ecológicas e valor nutritivo da biomassa vegetal para tilápia do Nilo. Jaboticabal: Universidade Estadual Paulista, 2005. 132p. Tese (Doutorado em Aqüicultura) - Universidade Estadual Paulista 2005.

HENRY-SILVA, G.G. Utilização de macrófitas aquáticas flutuantes (Eichhornia crassipes, Pistia stratiotes e Salvinia molesta) no tratamento de efluentes de piscicultura e possibilidades de aproveitamento da biomassa vegetal Jaboticabal: Universidade Estadual Paulista, 2001. 56p. Dissertação (Mestrado em Aqüicultura) - Universidade Estadual Paulista, 2001

HENRY-SILVA, G.G.; CAMARGO, A.F.M. Composição química de quatro espécies de macrófitas aquáticas e possibilidades de uso de suas biomassas. Naturalia, v.26, p.111-125, 2000.

HENRY-SILVA, G.G.; CAMARGO, A.F.M. Valor nutritivo de macrófitas aquáticas flutuantes (Eichhornia crassipes, Pistia stratiotes e Salvinia molesta) utilizadas no tratamento de efluentes de aqüicultura. Acta Scientiarum, v.24, n.2, p.519$526,2002$.

HOSSAIN, M.A.; JAUNCEY, K. Studies on the protein, energy and amino acids digestibility of fish meal, mustard oilcake, linseed and sesame meal for common carp (Cyprinus carpio). Aquaculture, v.83, p.59-72, 1989. 
LANNA, E.A.T.; PEZZATO, L.E.; CECON, P.R. et al. Digestibilidade aparente e trânsito gastrointestinal em tilápia do Nilo (Oreochromis niloticus), em função da fibra bruta da dieta. Revista Brasileira de Zootecnia, v.33, n.6, p.21862192, 2004.

LANNA, E.A.T.; PEZZATO, L.E.; FURUYA, W.M. et al. Fibra bruta e óleo $\mathrm{m}$ dietas práticas para alevinos de tilápia do Nilo (Oreochromis niloticus). Revista Brasileira de Zootecnia, v.33, n.6, p.2177-2185, 2004.

MACKERETH, F.I.F.; HERON, J.; TALLING, J.F. Water analysis: some revised methods for limnologist. London: Freswater Biological Association, 1978. 121p.

MATSUMOTO, T.; RUCHIMAT., T.; ITO, Y. et al. Amino acid availability values several protein sources for yellowtail (Seriola quinqueradiata). Aquaculture, v.146, p.109-119, 1996.

MIDLEN, A., REDDING, T. Environmental Management for Aquaculture. Netherlands: Kluwer Academic Publishers, 1998. $223 p$.

NACA/FAO. Aquaculture Development Beyond 2000: the Bangkok Declaration and Strategy. Conference on Aquaculture in the Third Millennium, Bangkok. NACA, Bangkok \& FAO, 2000. 27 p.

NAEGEL, L.C.A. Azolla meal as a supplemental feed ingredient for tilapias. In: INTERNATIONAL SYMPOSIUM ON TILAPIA IN AQUACUlture, 4., 1997, Orlando. Proceedings... Orlando: WAS, 1997. p.20-30.

NAKANISHI, L.I.T. Valor nutritivo da folha de mandioca, Manihot esculenta, em dietas de crescimento para o pacu, Piaractus mesopotamicus. Florianópolis: Universidade Federal de Santa Catarina, 1999. 83p. Dissertação (Mestrado em Aqüicultura) - Universidade Federal de Santa Catarina, 1999.
NOSE, T. Recent advances in the study of fish digestion in Japan In: SIMPOSIUM ON FIFISH NUTRITION AND FISH FEED TECHNOLOGY, 1966, Belgrade. Proceedings... Belgrade: EIFAC/FAO, 1966. p. 15 se II-7.

PEZZATO, L.E.; MIRANDA, E.C.; BARROS, M.M. et al Digestibilidade aparente de ingredientes pela tilápia do Nilo (Oreochromis niloticus). Revista Brasileira de Zootecnia, v.31, n.4, p.1595-1604, 2002.

SANTIAGO, C.B.; ALDABA, M.B.; REYES, O.S. et al. Response of Nile tilapia (Oreochromis niloticus) fry to diets containing Azolla meal. In: INTERNATIONAL SYMPOSIUM ON TILAPIA IN AQUACULTURE, 2., 1988, Philippines. Proceedings... Philippines: WAS, 1998. p.377-382.

VALENTI, W.C. Aqüicultura no Brasil; bases para um desenvolvimento sustentável. Brasília: $\mathrm{CNPq} /$ Ministério da Ciência e Tecnologia, 2000. 399p.

WEE, K.L. Used of non-conventional feed stuff of plant origin as fish feed - is it practical and economically feasible? In: DE SILVA, S.S. (Ed.) Fish nutrition. Manila: Asian Fisheries Society Special Publications, 1991. p.150-156. 